\title{
Enhancement of the Electrocatalytic Activity of Conducting Polymer/Pd Composites for Hydrazine Oxidation by Copolymerization
}

\author{
Shimaa M. Ali ${ }^{1,2, *}$, Khadija M. Emran ${ }^{1}$, Hamedh A. Al lehaibi ${ }^{1}$ \\ ${ }^{1}$ Department of Chemistry, Faculty of Science, Taibah University, Madinah 30002, KSA \\ ${ }^{2}$ Department of Chemistry, Faculty of Science, Cairo University, Giza 12613, Egypt \\ *E-mail: dr_shimaaali80@yahoo.com
}

doi: $10.20964 / 2017.09 .73$

Received: 27 April 2017 / Accepted: 23 July 2017 / Published: 13 August 2017

\begin{abstract}
Poly(ANI-co-Py)/Pd composite was prepared by electrochemical polymerization from a mixed monomer solution in $0.5 \mathrm{M} \mathrm{LiClO}_{4} /$ acetonitrile. The prepared composite was investigated as a catalyst for the electrooxidation of hydrazine by cyclic voltammetry (CV) and electrochemical impedance spectroscopy (EIS). Scanning electron microscope (SEM) photos showed that Pd particles are uniformly distributed over the rough copolymer surface. The electrocatalytic activity of the prepared composite was compared with those of individual polymers composites, polyaniline/Pd (PANI/Pd) and polypyrrole/Pd (PPY/Pd). It was proved that the copolymerization enhanced the electrocatalytic activity toward hydrazine oxidation as indicated by the increased oxidation peak current in $\mathrm{CV}$ and the reduced charge transfer resistance determined by EIS. The optimum $\mathrm{pH}$ for performing the hydrazine oxidation by the proposed catalyst is 6 . Kinetic study shows that the process is diffusion-controlled with a diffusion coefficient value of $1.94 \times 10^{-4} \mathrm{~cm}^{2} \mathrm{~s}^{-1}$. A linear calibration curve was obtained between $3 \mathrm{mM}$ and $0.01 \mathrm{M}$ with a sensitivity value of $98.31 \mu \mathrm{A} \cdot \mathrm{mM}^{-1}$ and a limit of detection (LOD) value of $0.38 \mu \mathrm{M}$. The presented composite showed good stability, reproducibility, and selectivity for hydrazine oxidation.
\end{abstract}

Keywords: conducting polymers; palladium-based sensor; composite; hydrazine oxidation.

\section{$\underline{\text { FULL TEXT }}$}

(C) 2017 The Authors. Published by ESG (www.electrochemsci.org). This article is an open access article distributed under the terms and conditions of the Creative Commons Attribution license (http://creativecommons.org/licenses/by/4.0/). 